\title{
Distributional effects of carbon taxation in passenger transport with lump-sum offset: low income households, retirees and families would benefit in Germany
}

\author{
Christine Eisenmann $^{1 *} \mathbb{D}$, Felix Steck ${ }^{1}$, Lars Hedemann ${ }^{1}$, Barbara Lenz ${ }^{1}$ and Florian Koller ${ }^{2}$
}

\begin{abstract}
Background: The introduction of a carbon tax on passenger transport is currently being discussed in Germany. Various stakeholders favour a consumption-based, revenue-neutral carbon tax with a uniform lump-sum offset for private households and a tax rate of $40 €$ per ton of $\mathrm{CO}_{2}$.

Objective: In this study, we examine the distributional effects of carbon taxation for the German passenger transport sector under the assumption of the proposed tax model. We discuss as to what extent which socioeconomic groups would be burdened and who might even benefit from carbon taxation. To answer these questions we use a uniquely modelled data set that encompasses all forms of passenger transport (i.e. in Germany and abroad) of the German resident population over 1 year. The national household travel survey Mobility in Germany 2017 is the basis of the microscopic data set. We derive annual $\mathrm{CO}_{2}$ emissions and carbon tax burdens for various population groups using the data on passenger transport, as well as specific emission factors.

Results: Results show that low income households, retirees, single parents and family households with two or more children would benefit from the proposed carbon taxation scheme due to below-average emissions per person; in contrast, working age households without children and car owners with heavy car use would be burdened. Our results are of particular relevance to transport researchers, transport politicians and decision makers as a basis for designing, developing and introducing a carbon taxation scheme.
\end{abstract}

Keywords: Mobility in Germany 2017, $\mathrm{CO}_{2}$ emissions, Passenger transport, Carbon tax, Distributional effects, Transport policy

\section{Introduction}

Within the framework of the Climate Protection Plan 2050, the German Federal Government has set itself the goal of reducing greenhouse gas (GHG) emissions across multiple sectors by $80 \%$ to $95 \%$ by 2050 , compared to 1990 [1]. In contrast to other sectors, the German

\footnotetext{
* Correspondence: christine.eisenmann@dlr.de

Please note that the Co-author Lars Kröger got married some weeks ago and changed his last name to Hedemann

${ }^{1}$ Institute of Transport Research, German Aerospace Center, 12489 Berlin,

Germany

Full list of author information is available at the end of the article
}

transport sector has not contributed to a GHG reduction in recent years [2]. In certain areas, total $\mathrm{CO} 2$ emissions have remained static, as in road transport or have even risen significantly, as in aviation.

Recently, various stakeholders have been controversially discussing how to achieve the climate targets; amongst them are environmental non-governmental organizations, the Fridays for Future movement and political parties. A popular measure demanded by many stakeholders is the introduction of a $\mathrm{CO}_{2}$ pricing system in the form of a carbon tax for private households in 
various sectors, such as the transport sector, the energy sector or the housing sector.

In fact, the introduction of broad carbon taxation in Europe has been discussed since the early 1990s [3]. At that time, for Germany and other European countries, many experts claimed potential carbon emission savings of $10 \%$ to $20 \%$ compared to a business-as-usual baseline if applied to production and consumption [4-6].

For the transport sector, a more recent study by Andersson [7] revealed that, for the time between 1990 and 2005, the introduction of a broad carbon tax in Sweden actually led to an average reduction of $6.3 \%$ in transport $\mathrm{CO}_{2}$ emissions (i.e., metric tons per capita) compared to a hypothetical state without levying the tax. Moreover, the reduction revealed a positive trend and increased up to $9.4 \%$ in the year 2005 . For the transport sectors of other countries, such as China or India, saving potentials of up to $40 \%$ by 2050 were suggested recently $[8,9]$. Thus, broad carbon taxation is able to successfully reduce $\mathrm{CO}_{2}$ emissions in the transport sector.

However, carbon taxation is prone to regressiveness $[4,10,11]$, especially in the transport sector [5]. That is, tax burden might be distributed disproportionately among population groups and particularly vulnerable groups might be negatively affected in terms of welfare. For example, low-income groups might be worse off compared to higher-income groups, rural households might be worse off compared to urban households, households with children and especially single parents might be worse off compared to households without children, and the elderly might be worse off compared to younger individuals. Thus, equality related to transport payments might be violated [12].

Indeed, regressiveness can be compensated by recycling carbon tax revenues, e.g., a lump-sum redistribution or other tax break [13]. Yet, even if models of compensation for vulnerable groups are installed, regressive effects may remain. For example, carbon taxation worsened the welfare condition of Danish low-income deciles although balancing measures, namely an income tax reduction for low incomes and increased child support, were applied [14]. Irish rural households were shown to lose despite tax credits were given in compensation for a carbon tax on fuels [15]. Although the discussed uniform lump-sum transfers were shown to yield better results in general $[14,16]$ as well as for incremental transportation taxation [17-19], distributional effects of each carbon tax implementation need detailed attention [20].

The present study examines distributional effects of carbon taxation for the German passenger transport sector under the assumption of a recently discussed tax model. In particular, the questions arise as to what extent which segments of the German population would be burdened and who might even benefit. The results are intended to provide a valuable data basis for transport researchers and decision makers. A second focus lies upon the demonstration of the method and data used in order to facilitate further analyses of alternative tax models.

\subsection{Underlying carbon tax model}

In principle, a tax model covers two aspects, tax levying and the use of tax revenues. Both bear various implementation options. A tax can be levied based on consumption or as a flat-rate taking certain characteristics into account. Tax revenues can be used to increase the general national household budget, to reduce national debts, to support investments into sustainable infrastructure and industries, or can be distributed to tax payers in order to offset their burden.

In this study, a consumption-based revenue-neutral carbon tax with a uniform lump-sum offset for private households referred to as climate premium is considered. A tax rate of $40 €$ per ton of $\mathrm{CO}_{2}$ is assumed, which is in the range of suggestions for an initial tax rate of various studies (e.g. [21] with $30 €$ per ton $\mathrm{CO}_{2}$, [22] with $50 €$ per ton $\mathrm{CO}_{2}$ ). These studies further suggest an increase of the tax level over later years. Similar to a VAT, the carbon tax applies to all modes of transport and will be levied on e.g. train tickets or fuel, taking into account the emissions caused. Tax revenues are fully recycled and distributed to households. In particular, every individual receives the same climate premium derived endogenously from the total carbon tax revenue and the population size. The considered carbon tax is calculated on top on existing taxes for each fuel type. So, the existing tax system remains unchanged and no cross effects by tax reductions for particular fuel types have to be taken into account. In order to investigate distributive effects of carbon taxation, net effects of leveraging and the use of revenues of taxation need to be calculated. Net effects result from the income of each household from the climate premium minus carbon tax paid. In this study, net effects are derived at the household level and then normalized to net effects per capita per year.

The carbon tax considered in this analysis intends to mitigate social hardships, to avoid a prejudice to the calculation of income, and to enforce the steering effect, e.g. [22]. Broad carbon taxation with revenue-neutral lump-sums are expected to yield better results in terms of social compatibility than alternate transport-related tax instruments, such as a kilometre-based toll or a vehicle purchase tax.

\subsection{Total passenger transport as data basis}

In order to support the current discussion, several studies have investigated the distributional effects of carbon taxation in Germany based on individual data on household expenditures [23-25]. By including other sectors than the 
transport sector, e.g. the heating sector, the analyses allow a more general focus on distributional effects of carbon taxation for German households. However, these studies show weaknesses in the representation of transportrelated emissions, since only household expenditures on fuel were included [23-25] and households were only grouped by their commuting distances [24]. The expenses for other modes of transport, such as air and rail travel, were not taken into account.

This study distinguishes itself by using a data basis that encompasses the complete mobility of the German resident population (in the year 2017). This data is representative of the total population, includes both everyday mobility (e.g. commuting, shopping) and longdistance journeys (e.g. annual holiday by plane) and includes all modes of transport (e.g. car, public transport, air travel). Thus, our approach of including all forms of passenger transport is holistic and does not focus only on one mode of transport or trip purpose. Moreover, the data of our analysis differs from the data of other studies by using a trip data set of all passenger transport in Germany rather than data on individual household expenditures [23-25]. This enables us to add specific emission factors to each trip differentiated by modes of transport or trip length. The data can be used to determine the transport demand volumes and emissions of various population groups with all modes of transport. This is the essential basis for assessing the distributional effects of carbon taxation in the transport sector.

\section{Methods}

Next, our data used for displaying passenger transport is presented, the determination of $\mathrm{CO}_{2}$ emissions and distributional net effects are described and determinations of household groups are introduced.

\subsection{Modelled data set for all forms of passenger transport} The dataset of our study is a modelled data set for all forms of passenger transport of the German resident population over 1 year. This data set covers the total passenger transport of the population living in Germany, correctly reproduces the transport volumes of other official sources on the transport demand and is representative of the German population in terms of their socioeconomic characteristics. The national household travel survey (NHTS) Mobility in Germany (MiD) 2017 is the basis of the microscopic data set [26]. Official statistics are used to calibrate transport volumes and socioeconomic characteristics.

The MiD is a nationwide, comprehensive survey on the travel behaviour and transport demand of the German residential population. The most recent survey was conducted in 2017; former surveys date back to 2002 and 2008. The MiD includes, amongst others, a trip diary module and an overnight journey module. In the trip diary module, all respondents are asked to report all their trips and trip properties (e.g. distances travelled, vehicles used) on a given day. In the overnight journey module, a subsample of the respondents was asked to report all their overnight journeys over a period of 3 months. The field phase of the MiD 2017 took place between May 2016 and September 2017. A mixed-mode approach was used for the MiD 2017: the participants took part in the survey either by paper and pencil questionnaire or by web questionnaire. A total of around 316,000 individuals from 156,000 households took part in MiD 2017 and reported 961,000 trips for their respective survey days. Information on about 39,000 overnight journeys is also included in the survey [26]. Both, everyday travel and overnight journeys are included in our modelled data set of all forms of passenger transport.

The model set for all forms of passenger transport of the German resident population over 1 year consists of three steps. In the first step, the MiD datasets are processed. Hence, the datasets are manipulated in such a way that they either only consist everyday trips without overnight stays (trip diary module) or that they only consist of overnight trips (overnight journey module) and account for all age groups. Here, various adaptions were necessary: For example, fractions of overnight journeys were deleted from the trip diary module. Also, overnight journeys of children younger than 14 years were imputed; these age groups were originally not included in the overnight journey module. Furthermore, the probability of being a car driver and respectively a car passenger was imputed for car journeys in the overnight journey module; this information was not explicitly surveyed in the overnight survey modules as respondents reported solely that the car was being used. In the second step, the datasets of both modules are merged into one synthetic trip dataset. This dataset contains the entire transport demand (scaled everyday trips \& overnight journeys) for 3 months. In the third step, the iterative proportional fitting approach is used to weight the synthetic trip data set until all given socio-economic and transport demand distributions are correct. Socioeconomic information that is considered in the iterative proportional fitting process is e.g. age, gender, economic status, household size, car ownership. Travel demand statistics, which are considered, are e.g. car mileage statistics, public transport statistics, air transport statistics.

The resulting data represents the state of travel demand of the population living in Germany in 2017. The so produced and reweighted trip dataset on every day and long distance travel included information on trip lengths, modes used and personal IDs. Those IDs correspond to the person IDs of the underlying MiD survey 
and allow therefore adding sociodemographic information from the MiD. The data are representative for Germany as a whole, but not for single states or cities as small-scale distribution weights were not implemented. Moreover, $\mathrm{CO} 2$ emissions related to infrastructure costs are not covered in the model. Changes in travel behaviour that may result from the introduction of carbon taxation and the consequent increase in mobility costs are not taken into account.

\subsection{Determination of $\mathrm{CO}_{2}$ emissions in the transport} sector

Based on data on transport demand and $\mathrm{CO}_{2}$ emission factors, $\mathrm{CO}_{2}$ emissions from transport are determined for various population groups. Using a tax model, we calculated average annual carbon tax burdens for various population groups. To determine the annual $\mathrm{CO}_{2}$ emissions of various population groups, we computed the annual $\mathrm{CO}_{2}$ emissions of a household group $i$ (Emissions E $_{i}$ ) by adding the products of the respective transport mile-

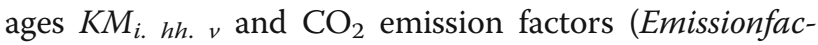
tor $\left._{1}, \ldots, n\right)$ of the modes of transport $v \in V$ of all households $i$. hh $i$. HH. The sum of all household groups produces TotalEmissions.

$$
\begin{aligned}
\text { Totalemissions } & =\sum_{i} \text { Emissions }_{i} \\
& =\sum_{i, h h} \text { Emissions }_{i . h h} \\
& =\sum_{i, h h} \sum_{v} K M_{i, h h, v} * \text { Emissionfactor }_{v}
\end{aligned}
$$

Afterwards, we aggregated the $\mathrm{CO}_{2}$ emissions per mode across the transportation modes. We calculated the annual $\mathrm{CO}_{2}$ emissions of cars, motorcycles and utility vehicles on a vehicle level (in $g \mathrm{CO}_{2} / v e h-k m$ ). ${ }^{1}$ The total emissions were assigned to the driver, which is suitable for our analysis on the household level. The final data of passenger transport in Germany differentiates ten modes of transport. Beside trips by common modes of transport, e.g. car, motorcycle and public transport, also private trips by utility vehicles or passenger ferries/ cruisers were reported, whereby the share of trips by utility vehicles and by passenger ferries/ cruisers is low with only $0.9 \%$ and $0.3 \%$ respectively.

Table 1 gives an overview of the emission factors used. Direct emissions, as well as emissions from evaporation and energy provision, are included in the emission factors used. Due to the importance of the private car for the mode choice, emission factors of car trips are determined in detail: for all cars in the data set, emission factors are supplemented and differentiated according to

\begin{tabular}{|c|c|c|c|}
\hline \multirow[t]{2}{*}{ Mode of transport } & \multicolumn{2}{|l|}{ Emission factor } & \multirow[t]{2}{*}{ Source } \\
\hline & Unit & Value & \\
\hline By foot & {$\left[g \mathrm{CO}_{2} / p-k m\right]$} & 0 & Own assumption \\
\hline Bicycle & {$\left[g \mathrm{CO}_{2} / p-k m\right]$} & 0 & Own assumption \\
\hline Car as driver & {$\left[\mathrm{g} \mathrm{CO}_{2} /\right.$ veh-km] } & $63-310$ & $\begin{array}{l}\text { Own calculations, } \\
\text { based on Ecke, } \\
\text { Chlond [27] and } \\
\text { Umweltbundesamt [28] }\end{array}$ \\
\hline $\begin{array}{l}\text { Motorcycle, } \\
\text { moped, scooter }\end{array}$ & {$\left[\mathrm{g} \mathrm{CO}_{2}\right.$, veh-km] } & 109 & $\begin{array}{l}\text { Own calculations, based } \\
\text { on Federal Ministry of } \\
\text { Transport and Digital } \\
\text { Infrastructure [29] }\end{array}$ \\
\hline $\begin{array}{l}\text { Local public } \\
\text { transit: bus }\end{array}$ & {$\left[g \mathrm{CO}_{2} / p-k m\right]$} & 75 & TREMOD 5.82 [30] \\
\hline $\begin{array}{l}\text { Local public } \\
\text { transit: tram, } \\
\text { subway }\end{array}$ & {$\left[g \mathrm{CO}_{2} / p-k m\right]$} & 64 & TREMOD 5.82 [30] \\
\hline Commuter train & {$\left[g \mathrm{CO}_{2} / p-k m\right]$} & 60 & TREMOD 5.82 [30] \\
\hline Long-distance bus & {$\left[g \mathrm{CO}_{2} / p-k m\right]$} & 32 & TREMOD 5.82 [30] \\
\hline Long-distance train & {$\left[g \mathrm{CO}_{2} / p-k m\right]$} & 36 & TREMOD 5.82 [30] \\
\hline Airplane & {$\left[g \mathrm{CO}_{2} / p-k m\right]$} & 201 & TREMOD 5.82 [30] \\
\hline $\begin{array}{l}\text { Passenger ferry, } \\
\text { cruiser }\end{array}$ & {$\left[g \mathrm{CO}_{2} / p-k m\right]$} & 115 & $\begin{array}{l}\text { Department of } \\
\text { Environment [31] }\end{array}$ \\
\hline Utility vehicle & {$\left[\mathrm{g} \mathrm{CO}_{2} /\right.$ veh- $\left.\mathrm{km}\right]$} & 372 & $\begin{array}{l}\text { Own calculations, } \\
\text { based on Federal } \\
\text { Ministry of Transport } \\
\text { and Digital } \\
\text { Infrastructure [29] }\end{array}$ \\
\hline
\end{tabular}

\footnotetext{
${ }^{1}$ vehicle kilometres
}

Table 1 Emission Factors Considered in the Study

vehicle characteristics. Therefore, we used the car usage and fuel consumption survey of the German Mobility Panel [27]. We estimated multivariate linear regressions with fuel consumption as the dependent variable. Independent variables are car drive, car size, and car age. We then applied the multivariate linear regression results to the car trips in our modelled dataset. Finally, we have transformed the fuel consumption results into emission factors using conversion factors for petrol and diesel, which also take the provision of energy into account. For battery electric vehicles we differentiated the emission factor by vehicle class, depending on their electric consumption and the average electricity mix of Germany in 2017 [28].

For public transport, we differentiated emission factors by trip distance and modes of transport used (i.e. street vs. rail). For the first $50 \mathrm{~km}$ of a public transit trip, we assigned the average emission factors of local public transit. For each additional kilometre of a trip, we assigned emission factors of long distance trains and long distance buses respectively. The German Regionalisation Act $(\operatorname{Reg} G)$ defines local public transit with a maximum length of $50 \mathrm{~km}$ or 1 hour of travel time [32]. This definition differs from the $100 \mathrm{~km}$ limit often used in transport science to define long distance trips [33]. 
Average emission factors per passenger kilometer were applied for the further modes of transport, e.g. airplanes, cruisers (Department of Environment, 2008; ifeu, 2018). Average emission factors of utility vehicles were determined from the mileage-weighted fuel consumption of utility vehicles up to 3.5 tons. The same approach was applied when determining the average emission factors of motorized two-wheelers (motorcycle, moped and scooter) [29].

\subsection{Calculation of distributional net effects}

For the analysis of distributional effects, net effects are calculated. These net effects are determined at the household level, because revenues (e.g. from salary) are mostly used and expenditures (e.g. on rent, food) are made at the household level, especially when individuals of a non-working age (e.g. children) live in the household. Net effects are the difference between the income of a household from the climate premium and the taxes paid. The net effect of a household is positive and leads to additional income when the average $\mathrm{CO}_{2}$ emissions of the individuals living in the household are lower than the average $\mathrm{CO}_{2}$ emissions of the total population. Negative net effects imply that the individuals living in the household exceed the average $\mathrm{CO}_{2}$ emissions of the total population; the carbon tax burden is hence higher than the climate premium. In order to compare the net effects independently of the size of the households, the following analyses refer to the average net effects per capita. It should also be noted that the individual carbon tax burdens of individual households may deviate from the average view, as these result from the households' specific travel behaviour.

The Climatepremium per capita is calculated by dividing the product of Totalemissions and the Taxrate by the Totalpopulation.

$$
\text { Climatepremium }=\frac{\text { Totalemissions } * \text { Taxrate }}{\text { Totalpopulation }}
$$

The net effect of a household group $i \operatorname{Neteffect}_{i}(E$ missions $\left._{i}\right)$ ) results from the difference between the products of the Climatepremium and the number of persons (summed up over the household sizes $\mathrm{HHsi}$ $z e_{i, h h}$ of all households) as well as the total emissions and the tax rate.

$$
\begin{aligned}
& \text { Neteffect }_{i}\left(\text { Emissions }_{i}\right) \\
& =\left(\text { Climatepremium } *_{i, h h} \text { HHsize }_{i, h h}\right)-\left({\text { Taxrate } \left.* \text { Emissions }_{i}\right)}\right)
\end{aligned}
$$

The net effect per capita (Neteffectpercapita ${ }_{i}$ (Emissions $\left.)_{i}\right)$ ) as a reference quantity is in turn the quotient of the net effect of a household group and the number of individuals in this group.

$$
\text { Neteffectpercapita }_{i}\left(\text { Emissions }_{i}\right)=\frac{\text { Neteffect }_{i}\left(\text { Emissions }_{i}\right)}{\sum_{i, h h} \text { HHsizee }_{i, h h}}
$$

\subsection{Definition of household groups}

For the analysis of net effects, households in the dataset are differentiated by their socio-economic characteristics. Table 2 shows descriptive statistics for all socioeconomic groups we included in our analyses. We have differentiated them by household income, household type, spatial type and car ownership/use. For these socioeconomic groups, the distribution of individuals and households in the sample, which is representative for German resident population, is presented.

For the analysis of interrelations between distributional effects and household income, households have been divided into five groups of equal size (quintiles) according to their net income equivalent per month. The OECD household equalized income is a measure to compare living standards irrespective of the size and composition of households. It is calculated by dividing the net income of the household by the weighted number of household members. Here, the first adult is counted with a weight of 1 , each additional adult with a weight of 0.5 and each additional minor with a weight of 0.3 .

The household type is also of interest for our analysis. Therefore, we differentiated households according to the number and age of individuals living in the household. Households with children, households with elderly individuals and working age households without children are the main groups which can be subdivided in 15 types of households.

Another category of interest is the spatial type, where the household is located. A new spatial classification (RegioStaR4) categorizes regions in Germany in four spatial types. It reaches from urban regions with metropolitan areas (1) and suburban areas (2) to rural areas close to urban regions (3) and peripheral rural areas (4) [34].

We have divided car owning households according to both, their number of cars and their car usage intensity, to take interrelations between net effects, car ownership and car use into account. To reflect car usage intensity, households were grouped into households with heavy car use (HCU households) and households with normal car use (NCU households). HCU households own at least one car with an annual mileage of $13,000 \mathrm{~km}$ or more. 
Table 2 Households and Individuals in the German Resident Population, Differentiated by Socioeconomic Group

\begin{tabular}{|c|c|c|c|}
\hline \multirow[t]{2}{*}{ Socioeconomic groups of households } & \multirow{2}{*}{$\begin{array}{l}\text { Number of individuals in Germany } \\
\text { [Mio.] }\end{array}$} & \multicolumn{2}{|c|}{ Number of households in Germany } \\
\hline & & [Mio.] & [\%] \\
\hline \multicolumn{4}{|c|}{ Differentiated by household income per month (OECD household equalized income) } \\
\hline 1. Quintile ( $\leq 1300 €)$ & 14.8 & 8.2 & 20 \\
\hline 2. Quintile (1301-1700 €) & 17.0 & 8.2 & 20 \\
\hline 3. Quintile (1701-2050 €) & 17.0 & 8.2 & 20 \\
\hline 4. Quintile (2051-2550 €) & 17.8 & 8.2 & 20 \\
\hline 5. Quintile ( $\geq 2551 €$ ) & 15.7 & 8.2 & 20 \\
\hline \multicolumn{4}{|l|}{ Differentiated by household type } \\
\hline Single-parents, 1 child & 0.9 & 0.5 & 1 \\
\hline Single-parents, $2+$ children & 1.3 & 0.4 & 1 \\
\hline Families, 1 child & 10.9 & 3.3 & 8 \\
\hline Families, 2 children & 11.8 & 3.8 & 7 \\
\hline Families, 3+ children & 4.6 & 0.9 & 2 \\
\hline 1-person household, $60+$ years, male & 3.0 & 3.0 & 7 \\
\hline 1-person household, $60+$ years, female & 5.4 & 5.4 & 13 \\
\hline $2+$-person household, youngest member $60+$ years & 14.8 & 7.4 & 18 \\
\hline 1-person household, 18-29 years & 1.5 & 1.5 & 4 \\
\hline 1-person household, 30-59 years & 6.6 & 6.6 & 16 \\
\hline 2-person household, youngest member 18-29 years & 2.8 & 1.4 & 3 \\
\hline 2-person household, youngest member 30-59 years & 9.1 & 4.5 & 11 \\
\hline $3+$-person household & 8.9 & 2.7 & 7 \\
\hline \multicolumn{4}{|l|}{ Differentiated by spatial type } \\
\hline Metropolitan urban region & 36.5 & 18.7 & 46 \\
\hline Suburban region & 16.4 & 8.2 & 20 \\
\hline Rural region located close to urban regions & 14.9 & 7.2 & 17 \\
\hline Peripheral rural region & 14.5 & 6.9 & 17 \\
\hline \multicolumn{4}{|l|}{ Differentiated by car ownership and car use } \\
\hline Non-motorized households & 12.7 & 9.2 & 22 \\
\hline NCU households, 1 car & 24.8 & 14.0 & 34 \\
\hline HCU households, $1 \mathrm{car}$ & 15.7 & 7.9 & 19 \\
\hline NCU households, $2+$ cars & 9.2 & 3.3 & 8 \\
\hline HCU households, $2+$ cars & 19.9 & 6.6 & 16 \\
\hline
\end{tabular}

NCU households own only cars with an annual mileage of less than $13,000 \mathrm{~km}$.

\section{Results}

In the following sections, the annual $\mathrm{CO}_{2}$ emissions in the transport sector are shown and the resulting distributional effects of introducing the considered carbon taxation model for various socioeconomic groups are examined. The $\mathrm{CO}_{2}$ emissions and the net effects of a climate premium are shown as average values for the respective population groups.

\section{$3.1 \mathrm{CO}_{2}$ emissions and place of residence}

The transport-specific $\mathrm{CO}_{2}$ emissions of the German population are 2.7 tons of $\mathrm{CO}_{2}$ per capita per year. At a $\mathrm{CO}_{2}$ price of $40 €$ per ton, annual tax revenues for the German federal government would amount to 9.0 billion $€$ (transport sector). The resulting climate premium is about $109 €$ per capita.

The average $\mathrm{CO}_{2}$ emissions per capita in the transport sector are slightly higher in rural than in urban regions (Fig. 1). However, the $\mathrm{CO} 2$ emissions (and transport demand) per person and mode of transport vary across spatial types. In all spatial types, car travel accounts for the 


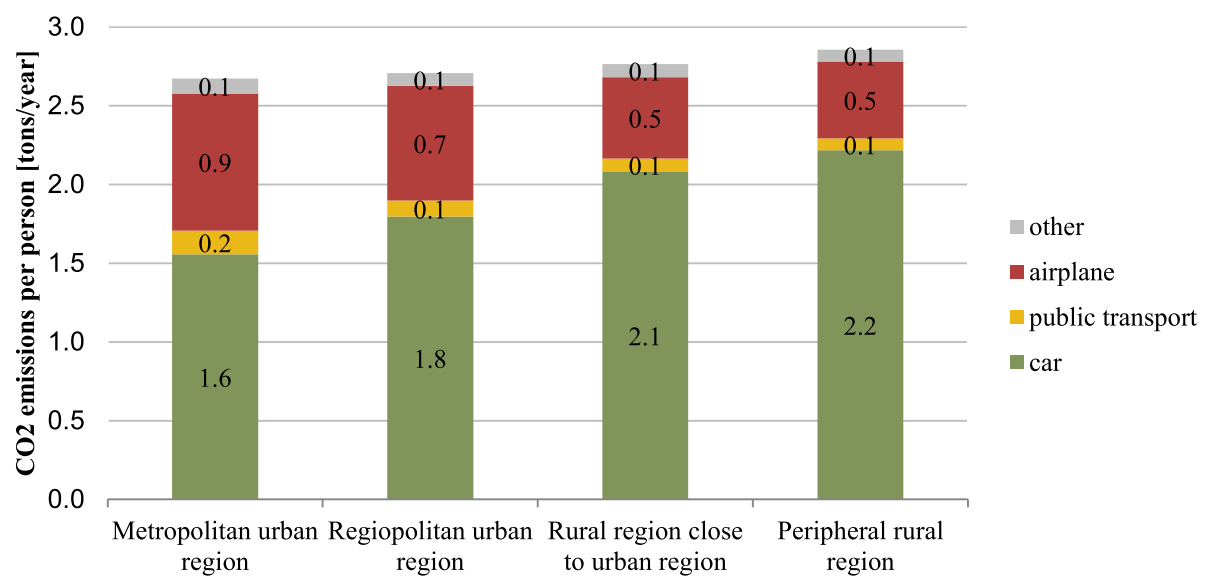

Fig. 1 Annual CO2 emissions per capita, differentiated by mode of transport and spatial type

majority of $\mathrm{CO}_{2}$ emissions. The share is largest in peripheral rural regions: on average, $78 \%$, respectively 2.2 of the $\mathrm{CO}_{2}$ emissions of inhabitants living in these regions are caused by car travel. In particular, the high $\mathrm{CO}_{2}$ emissions of aviation by inhabitants of metropolitan urban regions (0.9 tons per capita per year) are the main reason of their average annual $\mathrm{CO}_{2}$ emissions being at a similar level to the average $\mathrm{CO}_{2}$ emissions of the inhabitants of rural regions.

\subsection{Distributional effects and household income}

Next, distributional effects of various income groups are examined. Figure 2 shows that the net effect decreases with rising household income (i.e. OECD household equalized income) per month. Households in the lowest income quintile would benefit most from carbon taxation. Their average annual net effect is $42 €$ per capita. Hence, a carbon tax would increase the net equalized household income of households from the lowest income quintile by $0.5 \%$ on average. Households of the second and third income quintile would also achieve a positive net effect. In turn, households of the fourth and fifth income quintile would have average negative net effects.

However, a net effect of $-63 €$ per year is relatively modest compared to the income of households in the fifth quintile: their household net equalized income would only be reduced by about $0.2 \%$ on average.

\subsection{Distributional effects and household types}

Households can also be subdivided into household types according to their composition. The main characteristics for such a differentiation are the number of adults living in the household, the number of children living in the household and the age distribution of adults living in the household. This subdivision results in three main groups of households: Households with children, households with elderly individuals and working age households

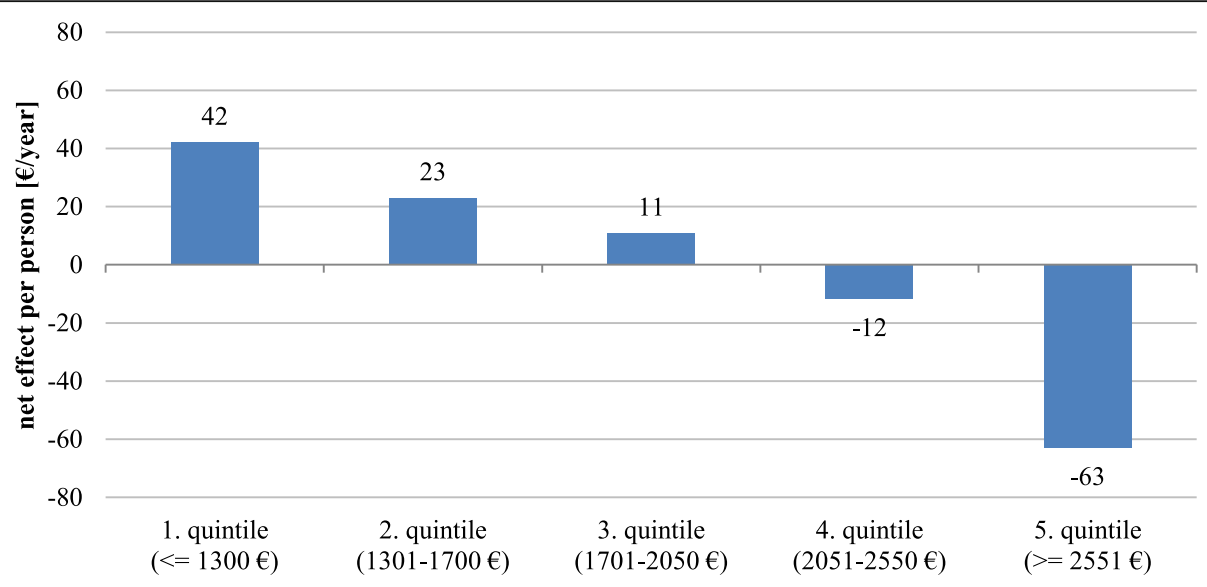

Fig. 2 Net effects of carbon taxation, differentiated by household income (OECD household equalized income) per month 


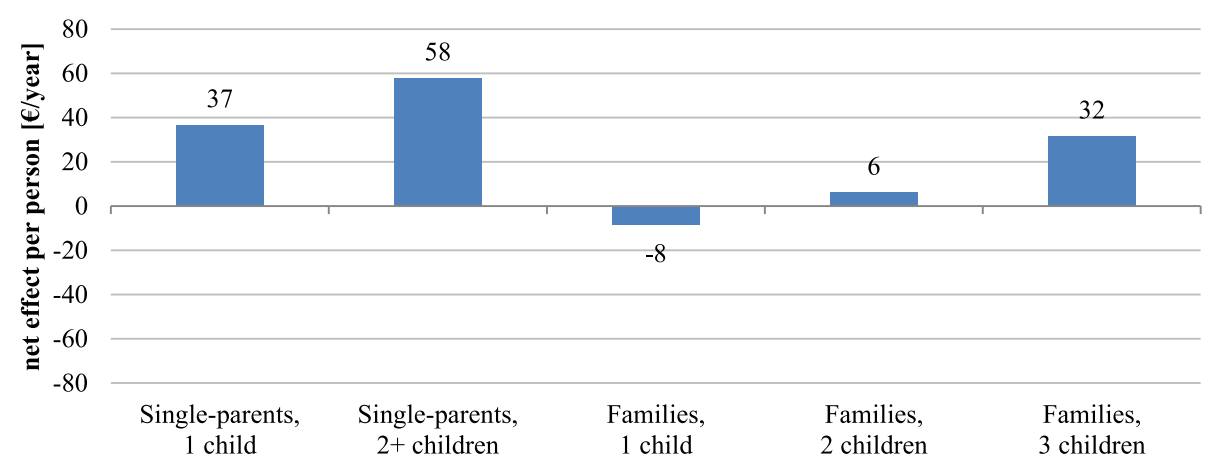

a) Households with children

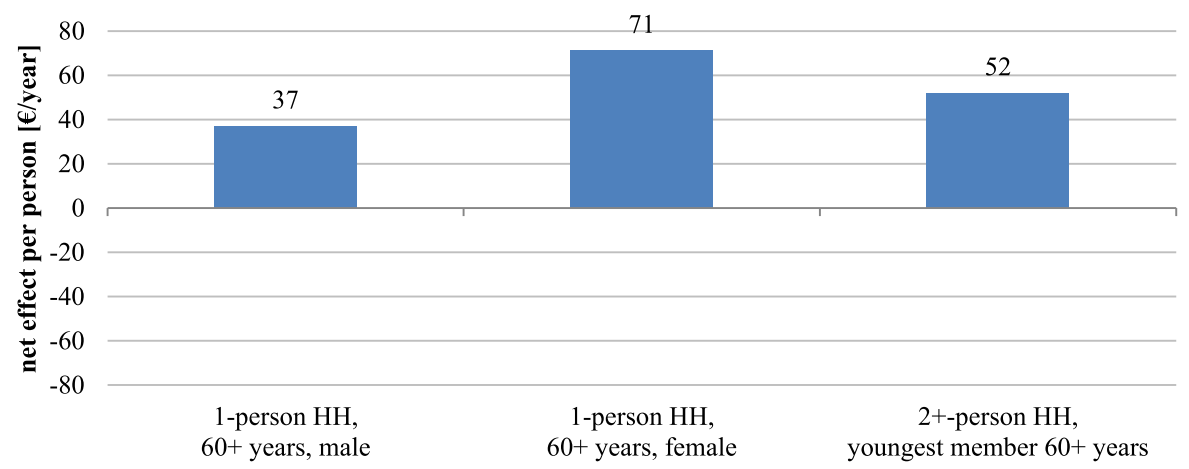

b) Households with elderly individuals

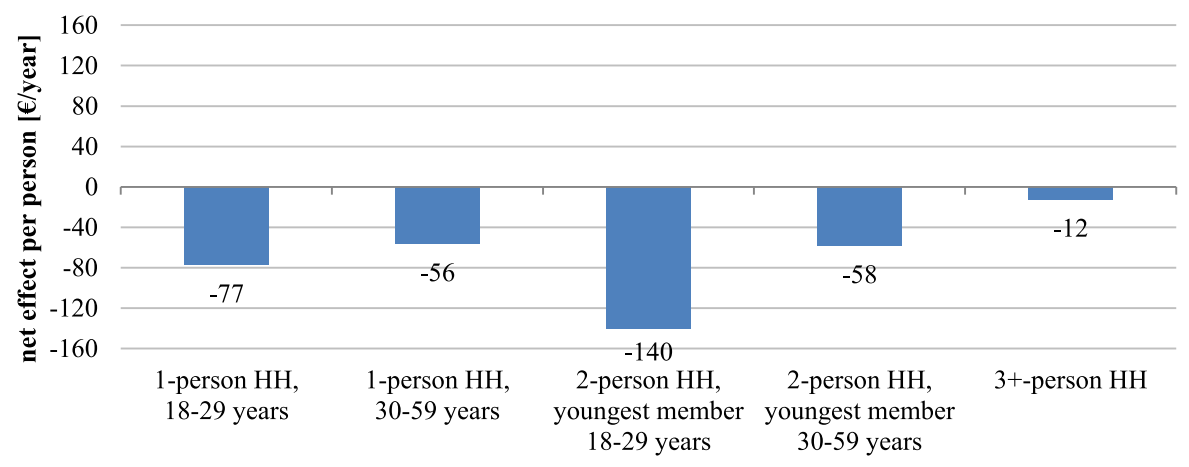

c) Working age households without children

Fig. 3 Net effects of carbon taxation, differentiated by household types. a Households with children. b Households with elderly individuals. $\mathbf{c}$ Working age households without children

without children. These groups in turn include a range of household types (see Fig. 3a-c).

Figure 3a indicates that most households with children would benefit from a carbon tax. The exceptions are family households with two parents and one child, for which the average net effect is negative $(-8 €$ per capita per year). Moreover, the positive net effect per capita increases with the number of children in the household. The lowest average $\mathrm{CO}_{2}$ emissions per capita are caused by households with single parents and one or more children. The low $\mathrm{CO}_{2}$ emissions of this household group can in turn be linked to the income effect shown in the previous section: single parents, for example, have on average only $75 \%$ of the net equalized household income of family households with two adults at their disposal.

Another important population group is elderly individuals, accounting for 39\% of all households in Germany. A carbon tax would lead to a positive net effect per capita for this population group (Fig. 3b). Amongst the group of households with elderly individuals, the lowest emissions are caused by elderly women living alone; this results in an average net effect of $71 €$ per capita. Multi- 
person households would receive an average net effect of $52 €$ and single-male households would receive $37 €$ on average.

In addition to family households with children and households with elderly individuals, households of working age without children constitute a third group. Figure $3 c$ shows that households with young adults (18-29 years) have very high negative net effects. For young two-person households, the net effects (i.e. measured per capita) are significantly more negative $(-140 €)$ than for young adults living alone $(-77 €)$. One- and two-person households without middle-aged adults also have negative net effects, although this is less pronounced than among young adults.

Further analyses have shown that employment in these middle-aged population groups has a decisive influence on the net effect. Households without employed persons have positive net effects; households with employed persons have negative net effects. The reasons are both the daily commuting distances and the higher purchasing power, which is reflected in higher long-distance travel demand.

\subsection{Distributional effects, car ownership and car use}

Car ownership has a substantial impact on the average $\mathrm{CO} 2$ emissions of a household, as the share of $\mathrm{CO} 2$ emissions caused by car use is highest in both urban and rural areas (see Fig. 1). Thus, not only the ownership of cars in the household but also the actual usage of a car impacts a household's annual $\mathrm{CO} 2$ emissions and thus the net effect. Figure 4 shows that heavy car use (HCU) households cause more $\mathrm{CO} 2$ emissions per capita than the population average. This applies in particular to households with more than one car: they have an average net effect of $-58 €$ per capita. Normal car use (NCU) households with two or more cars would be slightly burdened by carbon taxation $(-7 €$ on average).
NCU households with one car can, on the other hand, expect even a positive average net effect $(33 €)$.

Figure 5 expands this analysis by a spatial comparison. The net effects in all spatial areas decrease with an increasing number of cars in the household and a lower level of car usage. In all spatial types, average net effects are negative for households with heavy car usage (also households with one car). Households with two or more cars and heavy car usage, which are located in metropolitan and regiopolitan urban regions, have the most negative net effect (with a not negligible difference to households in rural areas). The net effect of nonmotorized households in urban regions is also lower than in rural regions. In both cases, this can be explained by the additional usage of other modes of transport (e.g. planes). However, this difference is lower or non-existent for households with normal car usage.

By comparing the differences of the net effects within each spatial type and within each car-ownership / usage category one might notice greater net effect dispersion for the car-ownership / usage category. Hence, car ownership and car usage have a considerably greater effect on the average $\mathrm{CO}_{2}$ emissions, and consequently on the net effects, than the location of the households.

In the case of households without cars, it is noticeable that households in peripheral rural regions generate the highest positive effect $(86 €)$ of all groups considered in Fig. 5.

\section{Discussion}

In this study, the distributional effects of revenueneutral carbon taxation with lump-sum offset for the German transport sector were investigated. Relying on the entire transport demand of the German population, i.e. everyday travel and long-distance journeys, per capita net effects were calculated for various socioeconomic groups.

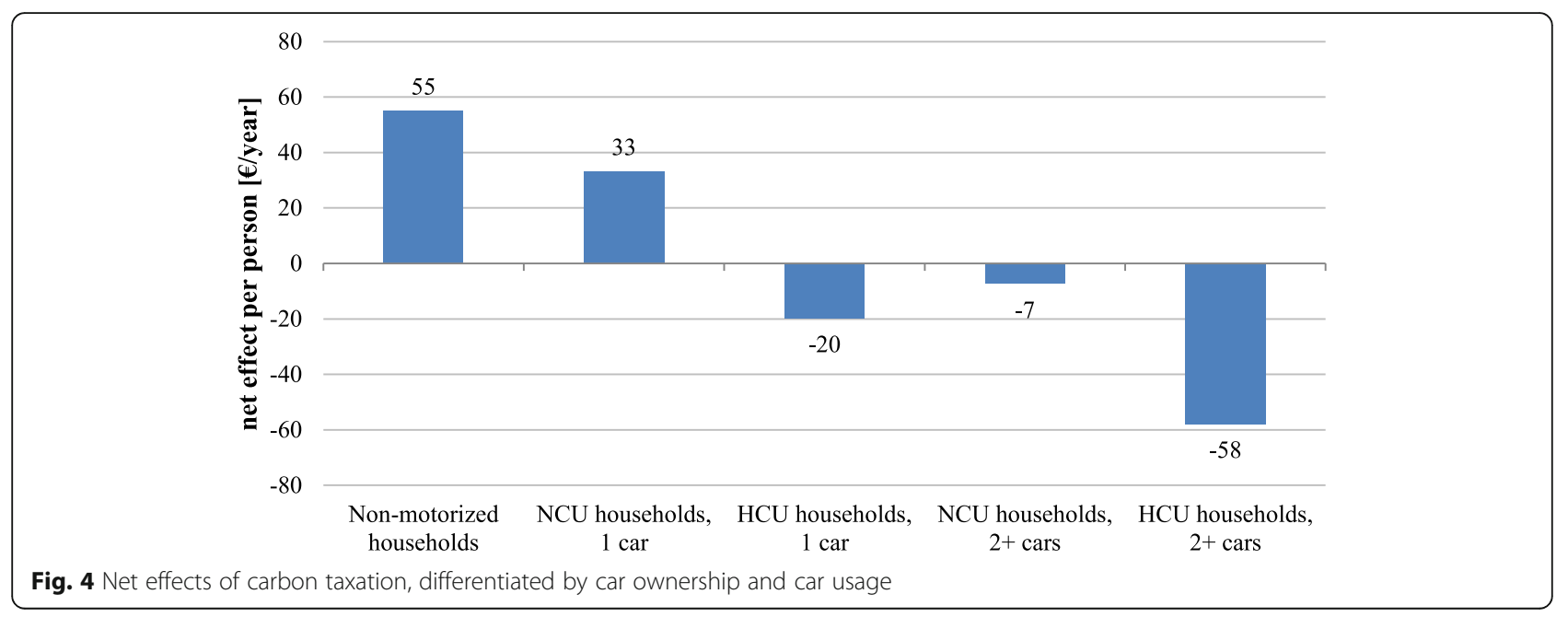




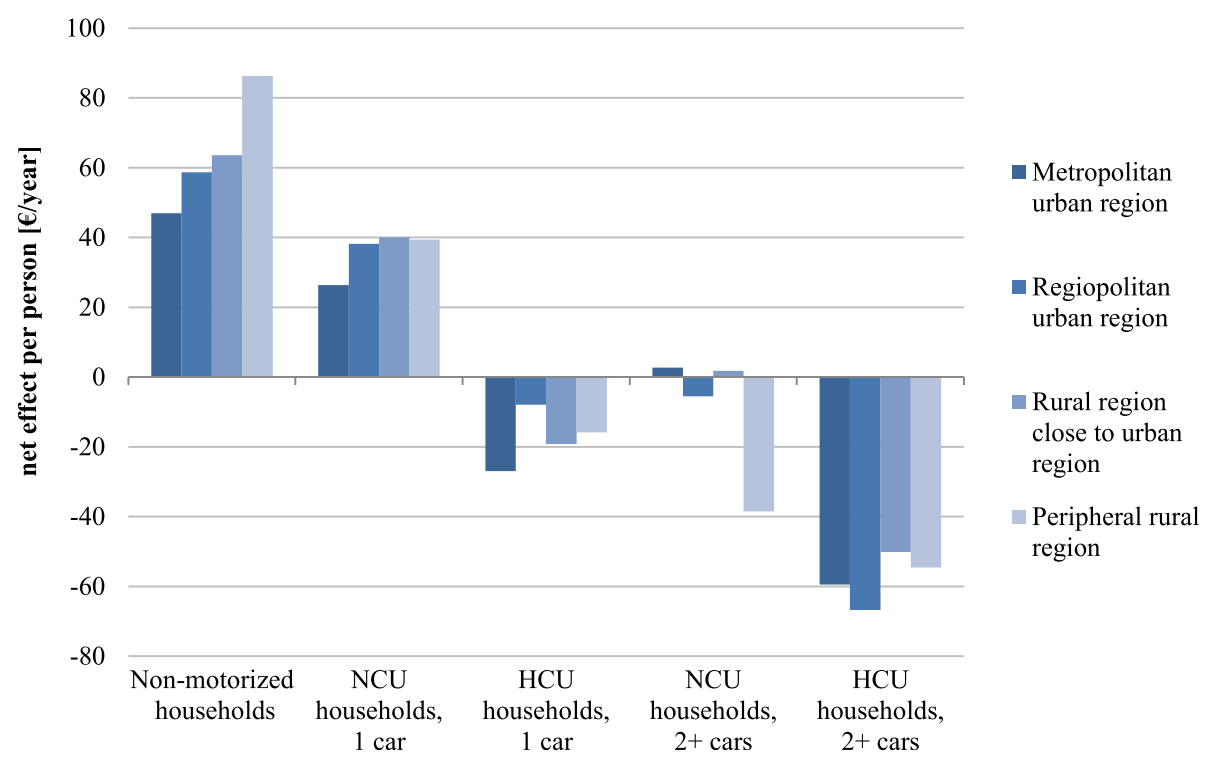

Fig. 5 Net effects of carbon taxation, differentiated by car ownership and car usage and spatial type

Firstly, net effects vary across income quintiles. The results suggest that households in lower-income quintiles would be better off with the implementation of the carbon tax with lump-sum offset. This is due to the fact that transport-related $\mathrm{CO}_{2}$ emissions increase with income, households in lower-income quintiles have lower than average emissions. Whereas, households in the highest quintile have above average emissions and, hence, would be worse off, i.e. they pay more carbon taxes than being refunded with the lump-sum resulting from the total carbon tax revenue. Our results echo with the simulation study of Bureau [35] on distributional effects when introducing a similar carbon tax in France. These effects can be explained by the fact that transport use increases with income.

Secondly, net effects were shown to vary across household types. Our results suggest that households with more than one child and especially single parents would benefit from the carbon tax. This is due to the fact that children's transport volumes are significantly lower than those of adults, and households with children cause fewer emissions per capita. As the climate premium is uniform across the population, compensation for parents is disproportionate. Further analyses of our modelled data set have revealed that working households without children would be worse off due to the fact that their members travel more by plane and travel to more distant destinations than other population groups.

Thirdly, the results suggest that elderly individuals, especially elderly women, would benefit from the carbon tax due to their low travel demand. The latter may be due to the disparities in the proportion of older women and men using cars [36].
Fourthly, our results indicate that households with more than one car and households with heavy car use would be worse off. However, the possession of more than one car or heavy car usage can be a consequence of few accessible alternatives, especially in rural areas. Rural households without cars would benefit the most but these households show significantly lower overall travel activities.

Lastly, the results indicate that rural households emit in total only slightly more as urban households, however, the share per mode of transport varies. Our analyses show also, that the socio-economic situation of a household might be a stronger explanation for a household's transport-related $\mathrm{CO}_{2}$ emission than the spatial type, e.g. the tax burdens for HCU households with two and more cars are similar in various spatial types.

\subsection{Practical implications}

In summary, the results identified the distribution of financial benefits and burdens related to passenger transport payments across German population groups resulting from broad carbon taxation. In order to decide whether this distribution is equitable, the additional definition of desired equity standards is required (cf. [12]), which is beyond the scope of this article. Nevertheless, the results suggest that the most vulnerable groups might not need specific protection against inequity in the proposed payment structure itself. Rather, inequality might be caused by underlying factors, such as accessibility or available resources and corresponding outcomes, which in turn result in the under-proportional burden of these groups. 
The applied method and the results facilitate an updatable dataset for analyzing and evaluating distributional effects of various policy instruments in passenger transport. For example, they provide a benchmark for testing other tax models, such as incremental taxation of transportation means, in particular, imposing additional taxes on car ownership [37], fuel [38], or air traffic.

\subsection{Limitations}

The main limitation of our study is that the underlying dataset on passenger transport only allows analyses on the level of population groups. Analyses at the level of individual survey participants are not possible as everyday travel (reported in the trip diary module) was scaled up from one survey day to 1 year and travel on overnight journeys was scaled up from three months to one year. Nevertheless, the occurrence of stationarity in transport demand, sufficiently large sample sizes and a distribution of survey periods over all days of the week and periods of the year allow for reliable results at group level. As a result, the analysis of distributional effects is limited to descriptive statistics; more sophisticated statistical analysis methods, such as regression models, would require longitudinal data per person over one or several weeks.

Secondly, the dataset represents the current travel demand volumes of the population living in Germany in 2017. Changes in travel behaviour that could result from the introduction of carbon taxation and the consequent increase in mobility costs are not taken into account. This article focused on the status quo, whereas travel demand models accounting for elasticities are needed to model changes in travel behaviour.

Thirdly, the challenges of tax implementation for the legislator are not in the focus of our analysis. Instead, we aim to contribute to the discussion on carbon taxation by pointing out distributional effects for population groups. When implementing the carbon taxation scheme, various issues, such as boundaries in the case of trans-national air travel, and transaction costs for introducing and administrating need to be taken into account.

Fourthly, the impacts of non-citizens (i.e. tourists) traveling within Germany and their payment of the carbon tax (e.g. when buying bus tickets or refuelling their cars) are not included in our analysis.

\subsection{Outlook}

By excluding trips over a certain distance, it is possible to limit the application of the proposed method geographically. If the taxation scheme is only applied to mobility within Germany or Europe, the net effects could be analysed as well. The exclusion of single modes of transport (e.g. air travel) or a separate report of $\mathrm{CO}_{2}$ emissions from specific travel purposes (e.g. business trips and journeys) would also be feasible.

For example, limiting the geographic scope of $\mathrm{CO}_{2}$ pricing to transport demand in Germany would reduce the income effect and increase the spatial effect. Therefore, the range of average net effects per capita between income groups would decrease from $105 €$ to $58 €$ (between first and fifth quintile); the range of net effects between spatial types would increase from $7 €$ to $20 €$ (between metropolitan rural regions and peripheral rural regions). The reason can be traced back to the volume of emissions: $\mathrm{CO}_{2}$ emissions of the urban population and the higher income groups result proportionately more from air travel, often to destinations abroad. The $\mathrm{CO}_{2}$ emissions of the rural population and the lower income groups result proportionately more from motorized private transport (see Fig. 1), usually within Germany. If the scope of a carbon tax was limited to travel demand in Germany, $\mathrm{CO}_{2}$ emissions from car travel would consequently carry greater importance. This example underlines that the definition of the geographic scope has a much greater influence on the social implications in the transport sector than in other sectors, such as the energy sector.

The methodology applied in this study represents the distributional effects of the potential introduction of a carbon tax in the actual transport situation. Elasticity effects, i.e. responses to demand for the tax-related increase in mobility costs, are not shown. If one were to assume another tax rate with the methodology presented (e.g. $180 €$ per ton instead of $40 €$ per ton), the net effects would increase proportionally with the tax rate in the analysis case presented here. An increase in the tax rate therefore does not lead to a change in the sign of the net effect of individual population groups and also the order remains identical. However, it is both conceivable and politically desirable for the population living in Germany to change their travel behaviour due to carbon taxation. Hence, [39] has shown for Canada that the tax rate must be at a certain level is necessary, e.g., in order to cause carbon emission reductions at all. The authors suggest Canadian $\$ 200$ per ton of $\mathrm{CO}_{2}$. Population groups could react in various ways to the $\mathrm{CO}_{2}$ pricing and rethink and change their travel patterns, modes of transport and destinations. For example, low-income population groups may react stronger than high-income population groups due to other demand elasticities. However, inhabitants of rural regions cannot adapt their travel behaviour as easily as those of urban regions due to the lack of alternatives. In total, this could change the order of those who would or would not profit. Nevertheless, similar to other countries such as Sweden, the effects of a carbon tax on emission reductions might be larger than expected as it "could be that the carbon tax 
induces a larger behavioural response than we assume from just looking at price elasticities of demand" [7].

\section{Conclusions}

In this study, we have analysed to what extent certain socioeconomic groups of the German resident population would be burdened and who might even benefit from carbon taxation in the transportation sector. We have assumed the carbon taxation scheme to be consumption-based and revenue-neutral with a uniform lump-sum offset for private households and a tax rate of $40 €$ per ton of $\mathrm{CO}_{2}$.

For the study, we utilized and analysed a dataset which contains annual $\mathrm{CO}_{2}$ emissions and the resulting net effects of the applied carbon taxation for various socioeconomic groups. Net effects are the difference between the income from the climate premium and the taxes paid. Net effects were derived at the household level and then normalized to net effects per capita per year. Our underlying source for travel demand is a uniquely modelled data set that encompasses all forms of passenger transport (i.e. in Germany and abroad) of the German resident population over 1 year. The NHTS Mobility in Germany 2017 is the basis of the microscopic data set. Mode specific $\mathrm{CO}_{2}$ emission factors were applied for the computation of annual $\mathrm{CO}_{2}$ emissions.

Our results show that low income households, retirees, single parents, and family households with two or more children, would benefit from the proposed carbon taxation scheme. Working age households without children, high income households and car owners with heavy car use, would be burdened from carbon taxation. Furthermore, average $\mathrm{CO}_{2}$ emissions of inhabitants from distinct spatial types are at similar levels, when taking their entire mobility (i.e. everyday travel, journeys to destinations within Europe and overseas) into account.

Our study is of particular relevance to transport researchers, transport politicians and decision makers as a basis for designing, developing and introducing a carbon taxation scheme. Moreover, the proposed methodology can be used and applied flexibly for various taxation schemes and tax rates. It could also serve as a blueprint for investigations into the distributional effects of carbon taxations in other countries.

\section{Abbreviations}

NHTS: National household travel survey; MiD: Mobility in Germany; RegG: German Regionalisation Act; RegioStaR4: Spatial classification for Germany; HCU households: Households with heavy car use; NCU households: Households with normal car use

\section{Acknowledgements}

Many thanks to Prof. Dr. Tobias Kuhnimhof for the idea and model implementation of the unique data basis for passenger transport of the German resident population over 1 year, which serves as the basis for our study. Many thanks to Dr. Christian Winkler, Viktoriya Kolarova, Stefan Seum and Angelika Schulz for the engaging and helpful discussions on carbon emissions and carbon taxations in the transport sector. We also thank two anonymous reviewers for their helpful comments and suggestions.

\section{Authors' contributions}

The authors confirm contribution to the paper as follows: study conception and design: CE, FS, LK, BL, FK; data preparation: CE, FS, LK; analysis and interpretation of results: $C E, F S, L K, B L, F K$; draft manuscript preparation: $C E$, FS, LK, FK. All authors reviewed the results and approved the final version of the manuscript.

\section{Funding}

This research was funded by DLR's programmatic research funds as part of the Helmholtz Association. Open access funding provided by Projekt DEAL.

\section{Availability of data and materials}

The datasets / model results analysed during this study are not publicly available.

\section{Competing interests}

The authors declare that they have no competing interests.

\section{Author details}

${ }^{1}$ Institute of Transport Research, German Aerospace Center, 12489 Berlin, Germany. ${ }^{2}$ Humboldt Universität zu Berlin, 12489 Berlin, Germany.

Received: 3 April 2020 Accepted: 28 August 2020

Published online: 21 September 2020

\section{References}

1. Federal Ministry for the Environment, N.C., Building and Nuclear Safety (2016). Klimaschutzplan 2050-Klimaschutzpolitische Grundsätze und Ziele der Bundesregierung, (p. 2018).

2. German Federal Environment Agency. (2019). National Inventory Report for the German greenhouse gas inventory 1990-2017. Dessau.

3. Klok, J. (2005). Energy taxation in the European Union: Past negotiations and future perspectives, (pp. 10-11). Madrid: Instituto de Estudios Fiscales.

4. Symons, E., Proops, J., \& Gay, P. (1994). Carbon taxes, consumer demand and carbon dioxide emissions: A simulation analysis for the UK. Fiscal Studies, 15(2), 19-43.

5. Barker, T., \& Koehler, J. (1998). Equity and ecotax reform in the EU: Achieving a 10 per cent reduction in $\mathrm{CO} 2$ emissions using excise duties. Fiscal StudiesFiscal Studies, 19(4), 19-43.

6. Edwards, T. H., \& Hutton, J. P. (1998). The Effects of Carbon Taxation on Carbon, Nitrogen, and Sulphur Pollutants in Europe: Combining General Equilibrium and Integrated Systems Approaches, in Discussion papers in economics, University of York.

7. Andersson, J. (2017). Cars, carbon taxes and CO2 emissions. London: Grantham Research Institute on Climate Change and the Environment.

8. Zhou, Y., et al. (2018). Exploring the impacts of a low-carbon policy instrument: A case of carbon tax on transportation in China. Resources, Conservation and Recycling, 139, 307-314.

9. Gupta, M., Bandyopadhyay, K. R., \& Singh, S. K. (2019). Measuring effectiveness of carbon tax on Indian road passenger transport: A system dynamics approach. Energy Economics, 81, 341-354.

10. Poterba, J. M. (1991). Tax policy to combat global warming: On designing a carbon tax. Cambridge: National Bureau of Economic Research.

11. Wang, Q., et al. (2016). Distributional effects of carbon taxation. Applied Energy, 184, 1123-1131.

12. Martens, K., J. Bastiaanssen, and K. Lucas, 2 - Measuring transport equity: Key components, framings and metrics, in Measuring Transport Equity, K. Lucas, et al., Editors. 2019, Elsevier. p. 13-36. https://doi.org/10.1016/C2017-0-01787-1

13. Baranzini, A., Goldemberg, J., \& Speck, S. (2000). A future for carbon taxes. Ecological Economics, 32(3), 395-412.

14. Klenert, D., \& Mattauch, L. (2015). How to make a carbon tax reform progressive: The role of subsistence consumption.

15. Scott, S., \& Eakins, J. (2004). Carbon taxes: Which households gain or lose? Wexford: Environmental Protection Agency.

16. Klenert, $D$, et al. (2018). Making carbon pricing work for citizens. Nature Climate Change, 8(8), 669-677. 
17. Labandeira, X., \& Labeaga, J. (1999). Combining input-output analysis and micro-simulation to assess the effects of carbon taxation on Spanish households. Fiscal Studies, 20(3), 305-320.

18. Brännlund, R., \& Nordström, J. (2004). Carbon tax simulations using a household demand model. European Economic Review, 48(1), 211-233.

19. Tiezzi, S. (2005). The welfare effects and the distributive impact of carbon taxation on Italian households. Energy Policy, 33(12), 1597-1612.

20. OECD (1999). Climate change, economic instruments and income distribution.

21. Fiedler, S., et al. (2018). Alternative Finanzierungsoptionen für erneuerbare Energien im Kontext des Klimaschutzes und ihrer zunehmenden Bedeutung über den Stromsektor hinaus Umweltbundesamt.

22. Sachverständigenrat zur Begutachtung einer gesamtgesellschaftlichen Entwicklung (2019). Optionen für eine CO2-Preisreform.

23. Zerzawy, F., \& Fiedler, S. (2019). Lenkungs- und Verteilungswirkungen einer klimaschutzorientierten reform der Energiesteuern.

24. Bach, S., et al. (2019). Für eine sozialverträgliche $\mathrm{CO}_{2}$-Bepreisung.

25. Gechert, S., et al. (2019). Wirtschaftliche Instrumente für eine klima- und sozialverträgliche CO2-Bepreisung. LOS 2: Belastungsanalyse.

26. Nobis, C., \& Kuhnimhof, T. (2019). Mobilität in Deutschland - MiD Ergebnisbericht, Studie von infas, DLR, INT und infas 360 im Auftrag des Bundesministeriums für Verkehr und Digitale Infrastruktur.

27. Ecke, L., et al., Deutsches Mobilitaetspanel (MOP) - Wissenschaftliche Begleitung und Auswertungen. Bericht 2017/2018: Alltagsmobilität und Fahrleistung. 2018: Karlsruhe, Germany.

28. German Federal Environment Agency. (2019). Entwicklung der spezifischen Kohlendioxid-Emissionen des deutschen Strommix in den Jahren 1990-2018. Dessau.

29. Federal Ministry of Transport and Digital Infrastructure (2018). Verkehr in Zahlen 2018/2019. Flensburg.

30. ifeu. (2018). TREMOD (transport emission model). Heidelberg and Dessau: on behalf of the German Federal Environment Agency.

31. Department of Environment, F.a.r.A (2008). 2008 guidelines to Defra GHG conversion factors: Methodology paper for transport emission factors. London.

32. Gesetz zur Regionalisierung des öffentlichen Personennahverkehrs (Regionalisierungsgesetz - RegG). Federal Office of Justice. Accessed 3 Mar 2020.

33. Axhausen, K. (2001). Methodological research for a European survey of longdistance travel personal travel. Washington, D.C: Transportation Research Board (Hg.): TRB Conference on Personal Travel: The Long and Short of It.

34. BMVI, RegioStaR Regionalstatistische Raumtypologie für die Mobilitäts- und Verkehrsforschung. German Federal Ministry for Transport and Digital Infrastructure: Bonn. Last accessed: July 1, 2020.

35. Bureau, B. (2011). Distributional effects of a carbon tax on car fuels in France. Energy Economics, 33(1), 121-130.

36. Zmud, J., et al. (2017). Still going ... And going: The emerging travel patterns of older adults, Institute for Mobility Research, Editor. Munich.

37. Fosgerau, M., \& Jensen, T. C. (2013). A green reform is not always green. Transportation Research Part C: Emerging Technologies, 30, 210-220.

38. Kim, Y.-D., Han, H.-O., \& Moon, Y.-S. (2011). The empirical effects of a gasoline tax on $\mathrm{CO} 2$ emissions reductions from transportation sector in Korea. Energy Policy, 39(2), 981-989.

39. Lee, M. (2013). Fair and effective carbon pricing: Lessons from BC. Canadian Centre for policy alternatives, BC Office. Ottawa.

\section{Publisher's Note}

Springer Nature remains neutral with regard to jurisdictional claims in published maps and institutional affiliations.

\section{Submit your manuscript to a SpringerOpen ${ }^{\circ}$ journal and benefit from:}

- Convenient online submission

- Rigorous peer review

- Open access: articles freely available online

- High visibility within the field

- Retaining the copyright to your article

Submit your next manuscript at $\boldsymbol{\nabla}$ springeropen.com 